\title{
Avaliação das emissões superficiais do gás de aterros sanitários de grande porte
}

\section{Evaluation of surface emissions of gas from large landfills}

\author{
Tiago Nascimento Silva \\ Engenheiro Ambiental pela Universidade São Marcos (USM). Oceanógrafo pela Universidade do Vale do Itajaí (Univali). \\ Mestre em Ciência e Tecnologia Ambiental pela Univali. Engenheiro de Valorização de Resíduos na ESTRE Ambiental S.A. - São Paulo (SP), Brasil. \\ Fernando Souza Nazareth de Freitas \\ Engenheiro Civil pela Fundação Armando Alvares Penteado (FAAP). Pós-graduado em Gestão Ambiental (Senac) \\ Coordenador Operacional na ESSENCIS Soluções Ambientais S.A. da CTVA - Caieiras (SP), Brasil.

\section{Giovano Candiani} \\ Ecólogo pela Universidade Estadual Paulista "Júlio de Mesquita Filho" (Unesp). Doutor em Energia pela Universidade Federal do ABC (UFABC). \\ Analista Ambiental na ESSENCIS Soluções Ambientais S.A. da CTVA - Caieiras (SP), Brasil.
}

\section{Resumo}

O presente trabalho apresentou os resultados das emissões de biogás pela superfície de dois aterros sanitários de grande porte. O trabalho consistiu na análise da fuga de biogás na superfície do aterro, por meio de uma placa de fluxo e análise laboratorial. A emissão média total no Aterro Bandeirantes foi de $0,00126 \mathrm{~m}^{3} \cdot \mathrm{CH}_{4} \cdot \mathrm{m}^{-2} \cdot \mathrm{h}^{-1}$ e no Aterro Caieiras de $0,01222 \mathrm{~m}^{3} \cdot \mathrm{CH}_{4} \cdot \mathrm{m}^{-2} \cdot \mathrm{h}^{-1}$. Com estes resultados foi possível determinar a fuga de biogás em ambos os locais. No Aterro Bandeirantes a fuga total de biogás representou $16 \%$ e no Caieiras, $35 \%$. As conclusões demonstraram que há uma perda significativa de biogás pela superfície dos dois aterros, comprometendo assim a eficiência do sistema de captação para aproveitamento do biogás.

Palavras-chave: aterro sanitário; biogás; metano; sistema de captação; emissão superficial; placa de fluxo.

\section{Abstract}

The present work showed the results of the biogas surface emissions from two large landfills. The study methodology consisted on escaping biogas analysis on the landfill surface, through the flux box and laboratory analysis. The total average emission of Bandeirantes Landfill was $0.00126 \mathrm{~m}^{3} \cdot \mathrm{CH}_{4} \cdot \mathrm{m}^{-2} \cdot \mathrm{h}^{-1}$ and in Caieiras Landfill it was of $0.01222 \mathrm{~m}^{3} \cdot \mathrm{CH}_{4} \cdot \mathrm{m}^{-2} \cdot \mathrm{h}^{-1}$. Those results were used to determinate the biogas escape both landfills. The total escape in Bandeirantes Landfill biogas accounted for $16 \%$ and in Caieiras, $35 \%$. The conclusions demonstrated that there is a significant loss of biogas through the surface in both landfills, thus compromising the efficiency of the capture for using biogas.

Keywords: landfill; biogas; methane; collection system; surface emission; flux box.

\section{Introdução}

Os resíduos sólidos urbanos são geralmente compostos por resíduos orgânicos, papéis, plásticos, madeiras, metais, vidros, entulhos, couro, tecidos, borrachas etc. O crescimento populacional, os hábitos culturais e sociais da população, as variações econômicas e a evolução tecnológica são fatores importantes para modificar a composição gravimétrica e a geração de resíduos sólidos urbanos (IPT, 2000).

No Brasil, a maior parte do resíduo sólido urbano destina-se aos aterros sanitários, sendo estes caracterizados como uma forma de disposição dos resíduos sólidos no solo, a qual, fundamentada em critérios de engenharia e procedimentos operacionais, permite o confinamento seguro. Isso garante o controle da poluição ambiental e minimiza os impactos ambientais (IPT, 2000; BOSCOV, 2008).

No aterro sanitário, a biodegradação dos resíduos sólidos urbanos ocorre por processos físicos, químicos e biológicos, produzindo chorume e gases. O processo de biodegradação dos resíduos orgânicos envolve diferentes processos ao longo do tempo, podendo ser dividido em fases (aeróbia, anaeróbia não metanogênica e metanogênica). Cada uma apresenta característica específica e tempo de duração. Os gases gerados nos aterros sanitários são compostos essencialmente de metano e gás carbônico. O gás metano $\left(\mathrm{CH}_{4}\right)$ é um dos responsáveis pelo efeito estufa, apresentando maior potencial de aquecimento global do que o gás carbônico $\left(\mathrm{CO}_{2}\right)$. Os aterros sanitários 
são responsáveis por até 20\% das emissões de metano geradas pelas atividades antrópicas (USEPA, 1998; 2005; IPCC, 2006; TEIXEIRA et al., 2009).

Uma parte do gás gerado no aterro sanitário atravessa o sistema de cobertura dos resíduos (camada de solo) e escapa para a atmosfera, mesmo quando o aterro sanitário apresenta um sistema de captação de biogás. Estes não são capazes de captar com muita eficiência (40 a 60\%), e parcelas significativas de metano são emitidas ao meio ambiente (SWANA, 1998; SPOKAS, et al., 2006; BABILOTTE, et al., 2010; MACIEL \& JUCÁ, 2011).

O sistema de cobertura dos resíduos é um dos mecanismos para evitar ou minimizar o escape de metano no aterro sanitário. No sistema convencional, os resíduos são cobertos com uma camada de solo compactada, formando uma barreira. Porém, ao longo do tempo e em contato com as condições ambientais, esta reduz a sua eficiência e, consequentemente, amplia a possibilidade de escape dos gases no aterro sanitário. Estudos realizados mostram que as taxas de emissões de metano em aterro sanitário variam de 0,004 a 14.794 g.m-2 , por dia (MARIANO, 2008; MARIANO \& JUCÁ, 2010; MACIEL \& JUCÁ, 2011). Tais variações nos valores das emissões de metano ocorrem devido a alguns aspectos relacionados à camada de cobertura (característica do solo, espessura, grau de compactação, etc.) no aterro, além da idade do resíduo, das características geotécnicas e dos aspectos climáticos (MARIANO \& JUCÁ, 2010).

Nesse contexto, a determinação do escape de metano em aterro sanitário contribui para monitorar a eficiência dos sistemas de captação de biogás, proporcionando maior disponibilidade de metano à comercialização dos créditos de carbono e geração de energia elétrica, a partir da combustão do metano em motores (MACIEL \& JUCÁ, 2011).

Assim, neste trabalho, apresentou-se uma avaliação das emissões fugitivas de metano pela camada de solo usada como cobertura final em dois aterros de resíduos sólidos urbanos de grande porte. Isso contribui para uma estimativa da determinação da eficiência dos sistemas de captação instalados para recuperação e aproveitamento do biogás na geração de créditos de carbono e/ou produção de energia elétrica.

\section{Materiais e métodos}

\section{Local de estudo}

O estudo foi realizado nos seguintes aterros sanitários: Bandeirantes e Caieiras. O Aterro Bandeirantes está localizado na Rodovia Bandeirantes, km 26, no município de São Paulo, estado de São Paulo. O Aterro Caieiras localiza-se na Rodovia Bandeirantes, km 33, no município de Caieiras, também em São Paulo.

O Aterro Bandeirantes foi implantado em 1978 e operou até 2007. Durante sua vida útil, este recebeu aproximadamente $30 \mathrm{mi}-$ lhões de toneladas de resíduos sólidos urbanos. Este aterro ocupa uma área de 140 hectares, e o maciço sanitário apresenta cerca de 90 m. O Aterro Caieiras foi instalado em 2002, ocupa uma área de 350 hectares. Atualmente, recebe 7.000 toneladas de resíduos sólidos urbanos por dia, atendendo principalmente o município de São Paulo. De 2002 até 2012, foram tratados cerca de 13 milhões de toneladas de resíduos, apresentando um maciço sanitário de aproximadamente $60 \mathrm{~m}$. Tal aterro apresenta estimativa de vida útil de aproximadamente 20 anos.

Os procedimentos operacionais nos dois aterros são similares. Após o recebimento dos resíduos, estes são compactados e cobertos por uma camada de solo com aproximadamente $50 \mathrm{~cm}$ de espessura. A característica do solo nos dois aterros também é semelhante, sendo classificado como silte argiloso (TEIXEIRA et al., 2009).

Ambos os aterros apresentam sistemas ativos de captação do biogás, com comercialização de créditos de carbono por meio do mecanismo de desenvolvimento limpo, sendo que, no Aterro Bandeirantes, existe a produção de energia elétrica (termoelétrica) e, no Caieiras, atualmente, está em fase de licenciamento ambiental uma unidade de geração de energia elétrica.

\section{Ensaios com placa de fluxo}

\section{Análise em campo}

As determinações dos fluxos de escape do metano, por meio da camada de solo da cobertura nos dois aterros, foram realizadas utilizando-se a metodologia do ensaio com placa de fluxo (TEIXEIRA et al., 2009; MARIANO \& JUCÁ, 2010; MACIEL \& JUCÁ, 2011). A placa de fluxo foi construída com chapa de aço galvanizada, medindo $84 \mathrm{~cm}$ de comprimento, $79 \mathrm{~cm}$ de largura e $5 \mathrm{~cm}$ de altura (0,66 $\mathrm{m}^{2}$ de área e 33,2 L de volume). Os pontos amostrados foram definidos de maneira a recobrir a maior parte da área total dos dois aterros sanitários (Figura 1). Para delimitar os pontos de amostragem, utilizou-se uma enxada. Em seguida, a placa de fluxo foi posicionada e, imediatamente, o solo foi retirado. Durante a instalação da placa, o solo foi recolocado e compactado manualmente em suas bordas, minimizando as trocas gasosas entre a placa de fluxo e o meio ambiente. Na parte superior da placa de fluxo existe um dispositivo de silicone, no qual se insere uma agulha hipodérmica para retirar uma alíquota do biogás. O procedimento de coleta foi realizado usando uma ampola gasométrica de vidro, com capacidade de $40 \mathrm{~mL}$ (Figura 1). As ampolas gasométricas são feitas de vidro com tampas rosqueadas de alumínio, apresentando válvula e acessórios que garantem a coleta e o armazenamento das amostras do biogás, sendo estas transportadas e analisadas em laboratório por meio de cromatografia gasosa. As amostras foram coletadas em quatro tomadas, com intervalos de um, dois e quatro minutos, a partir da tomada de tempo zero. A coleta neste intervalo de tempo é necessária para que não ocorra a saturação da concentração de metano na placa de fluxo. O resultado 
encontrado para a taxa de emissão média calculada nos pontos amostrados multiplicado pela área do aterro resulta em uma estimativa da taxa média de emissão de cada aterro (NETO, 2009).

\section{Análise em laboratório}

No laboratório, as amostras do biogás foram analisadas por meio de um cromatógrafo a gás, modelo U-13 (empresa Construmaq São Carlos, SP), que utiliza uma coluna cromatográfica empacotada com polímero HayeSep D e detector de ionização de chama com resolução (erro) de 100 ppb (partes por bilhão) de $\mathrm{CH}_{4}$. Os resultados obtidos do volume de metano foram expressos em partes por milhão (ppm), sendo usados para calcular as emissões fugitivas na camada de solo da cobertura nos aterros sanitários. Estas foram então mensuradas em metros cúbicos de gás por hora e por metro quadrado de solo amostrado. A pressão atmosférica e a temperatura ambiente foram medidas durante as análises laboratoriais. A placa de fluxo e o cromatógrafo utilizado para realizar as análises foram construídos pela empresa Construmaq São Carlos, SP.

\section{Metodologia do cálculo do fluxo de metano}

Os cálculos para a concentração do metano, medida em ppm, no ambiente dos aterros, foram feitos a partir de amostras de $40 \mathrm{~mL}$ coletadas do ar ambiente dos aterros sanitários, com anotação de condições ambientais do aterro (temperatura ambiente e do solo e pressão atmosférica).

Os cálculos para medir a concentração de metano tiveram como procedimento básico os seguintes parâmetros: temperatura ambiente média do aterro no dia da coleta, pressão atmosférica do ambiente do aterro e número de moles, obtido da análise cromatográfica para metano.

A medida de metano no ambiente dos aterros foi obtida por meio de uma amostra de ar, coletada a $2 \mathrm{~m}$ de altura da superfície do solo, as quais foram coletadas por meio de ampolas gasométricas e encaminhadas para análise cromatográfica no laboratório da empresa Construmaq São Carlos.

A partir dos resultados da concentração de metano obtidos das análises cromatográficas, foram considerados os quatro valores determinados em cada ponto amostrado, ao longo do tempo medido. Esses pontos foram plotados e analisados, atingindo-se um valor do coeficiente angular, que quantifica a taxa de emissão de metano do solo para a placa de fluxo.

Os cálculos para determinar as emissões de metano nos dois aterros foram realizados considerando as condições normais de temperatura e pressão (CNTP), sendo necessário inicialmente mensurar o número de moles de metano existente em 1 ppm do volume da placa (33,2 L). Foram consideradas as condições de pressão (684 mmHg) e temperatura (298,2 K) no laboratório onde foram realizadas as análises.
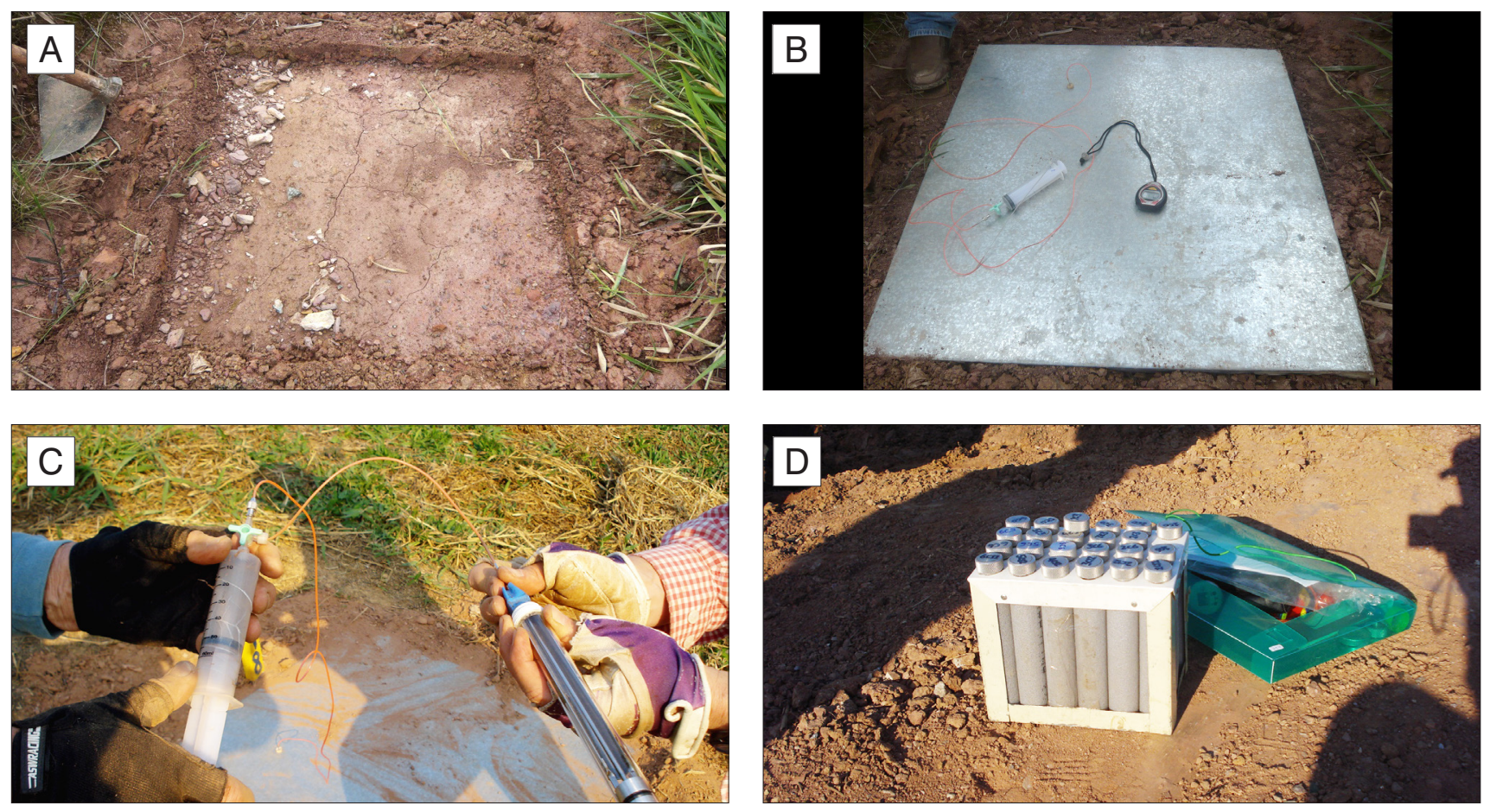

Figura 1 - Procedimento do ensaio da placa de fluxo e análise da emissão de metano pela camada de cobertura na superfície do aterro sanitário. (A) Instalação da placa de fluxo; (B) Coleta de amostra do biogás por meio da seringa; (C) Transferência da alíquota do biogás para a ampola gasométrica e (D) Acondicionamento das amostras do biogás na caixa de ampola gasométrica. 
A fim de determinar o número de moles, aplicou-se a equação de estado dos gases ideais (Equação 1), obtendo-se o número de moles por ppm. Considerando a quantia alcançada do coeficiente angular e multiplicando-a pelo número de moles, foi possível obter o número de moles de metano por minuto emitido em cada ponto de amostragem, ao longo do tempo medido (Equação 1):

$P V=n R T \Rightarrow V=\frac{n R}{P}$

onde:

$P$ : pressão atmosférica no aterro;

$V$ : volume;

n: número de moles;

$R$ : constante dos gases ideais $(62,4 \mathrm{mmHg})$ e

$T$ : temperatura (em graus $\mathrm{K}$ ).

Considerando as CNTP (pressão de $760 \mathrm{mmHg}$ e temperatura de 273,2 K), foi possível calcular o volume ocupado pelo número de moles, utilizando a Equação 1. Portanto, a emissão de metano foi expressa em metros cúbicos por hora, por metro quadrado de solo amostrado, levando-se em conta a área da placa $\left(0,66 \mathrm{~m}^{2}\right)$. A partir deste dado, calculou-se o número de moles em um mL, volume utilizado na injeção cromatográfica do ar ambiente do aterro. A concentração (ppm) do gás metano na atmosfera dos aterros foi calculada dividindo-se o número de moles do gás metano obtido na cromatografia pelo número de moles de ar em um mililitro do ar ambiente do aterro no ensaio (NETO, 2009).

Utilizando-se os dados obtidos, mensuraram-se as eficiências dos sistemas, considerando a eficiência total (baseada na vazão e emissão total) e a atual

\section{Pontos amostrados no Aterro Bandeirantes}

No Aterro Bandeirantes foi amostrado um total de 30 pontos (Figura 2), distribuídos da seguinte maneira:

- área 1 inclui 15 pontos no total de $121.522 \mathrm{~m}^{2}$, caracterizada pela disposição de resíduo mais recente (2004 a 2007);

- área 2 possui 15 pontos no total de $202.341 \mathrm{~m}^{2}$, caracterizada pela disposição de resíduo mais antigo (2000 a 2005).

\section{Pontos amostrados no Aterro Caieiras}

No Aterro Caieiras foi amostrado um total de 25 pontos (Figura 3), distribuídos da seguinte maneira:

- área 1 engloba a fase I, que ocupa um total de $55.000 \mathrm{~m}^{2}$, sendo depositadas 1.108 .000 toneladas (2002 a 2004);

- área 2 inclui fase II, que ocupa um total de $165.000 \mathrm{~m}^{2}$, sendo depositadas 3.500.000 toneladas (2005 a 2007);

- área 3 com a fase III, que ocupa um total de $110.000 \mathrm{~m}^{2}$, sendo depositadas 4.400 .000 toneladas (2008 a 2011).

\section{Resultados e discussão}

\section{Aterro Bandeirantes}

A Tabela 1 apresenta os resultados obtidos nos pontos amostrados pelos ensaios de campo do fluxo de metano.

Os valores foram calculados a partir das análises cromatográficas das amostras de cada um dos 30 pontos, durante as avaliações no laboratório. Foram tomadas as condições de pressão $(686,2 \mathrm{mmHg})$ e temperatura (293,8 K) nos ambientes predominantes.

Em cada um dos pontos amostrados, realizou-se o lançamento em gráfico dos quatro resultados tomados como série temporal da concentração (ppm) de metano (zero a quatro minutos), sendo possível determinar um valor de coeficiente angular ( $\left.\mathrm{ppm} \mathrm{CH}_{4} \cdot \mathrm{min}^{-1}\right) \mathrm{em}$

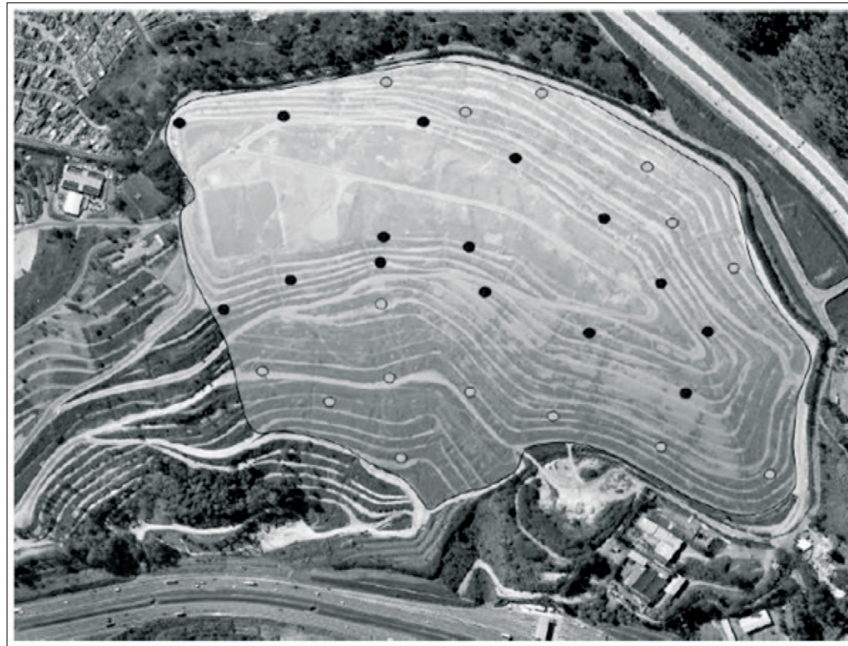

- Pontos de emissões em área com disposição de resíduo mais recente - Área 1 - Pontos de emissões em área com disposição de resíduo mais antigos - Área 2

Figura 2 - Pontos de análise do biogás na superfície do Aterro Bandeirantes. Fonte: Google Earth (2011).

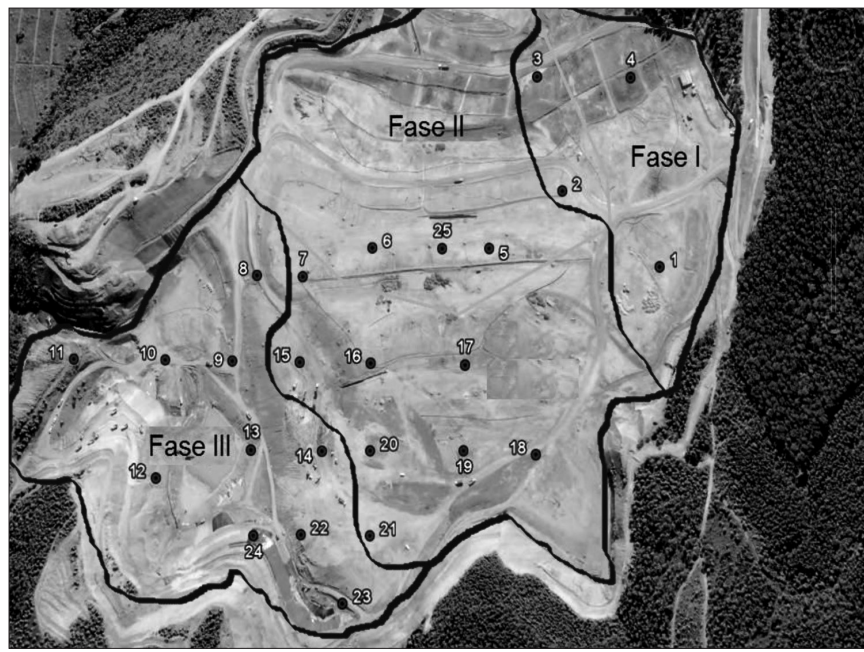

Figura 3 - Pontos de análise do biogás na superfície do Aterro Caieiras. Fonte: Google Earth (2011). 
cada ponto. Para demonstração desse cálculo, utilizou-se o ponto 2 da Tabela 1 como exemplo (Figura 4).

A partir de tais resultados obtidos em cada um dos pontos amostrados, foi possível calcular o número dos moles de metano por volume. Considerando as CNTP, foi necessário determinar inicialmente quantos existem em 1 ppm do volume (33,2 L) da placa de fluxo. Já com os valores de pressão e temperatura no laboratório e a Equação 1, foi possível obter o número de moles $\mathrm{CH}_{4} / \mathrm{ppm}$. Utilizando o valor obtido de coeficiente angular e o número de moles de metano ao longo do tempo amostrado, mensurou-se os moles de $\mathrm{CH}_{4} \cdot \mathrm{min}^{-1}$. Nas CNTP (760 mmHg de pressão e 273,2 K de temperatura), utilizando a Equação 1, pode-se determinar o volume que o número de moles obtido ocupa. Assim, a emissão de metano expressa em $\mathrm{m}^{3} \cdot \mathrm{CH}_{4} \cdot \mathrm{m}^{-2} \cdot \mathrm{h}^{-1}$ de solo amostrado em função da área da placa de fluxo $\left(0,66 \mathrm{~m}^{2}\right)$ foi determinada.

A média geral da emissão de metano medida foi de $0,00126 \mathrm{~m}^{3} \cdot \mathrm{CH}_{4} \cdot \mathrm{m}^{-2} \cdot \mathrm{h}^{-1}$. A emissão média de metano na área 1 (resíduo mais recente) foi de $0,00054 \mathrm{~m}^{3} \cdot \mathrm{CH}_{4} \cdot \mathrm{m}^{-2} \cdot \mathrm{h}^{-1}$ e na 2 (resíduo mais antigo), 0,00198 $\mathrm{m}^{3} \cdot \mathrm{CH}_{4} \cdot \mathrm{m}^{-2} \cdot \mathrm{h}^{-1}$ (Tabela 1). No Aterro Bandeirantes a área 1 é caracterizada pela deposição do resíduo mais recente (três a seis anos) e a 2, por aquela mais antiga (7 a 12 anos). Comparativamente, a emissão de metano é menor

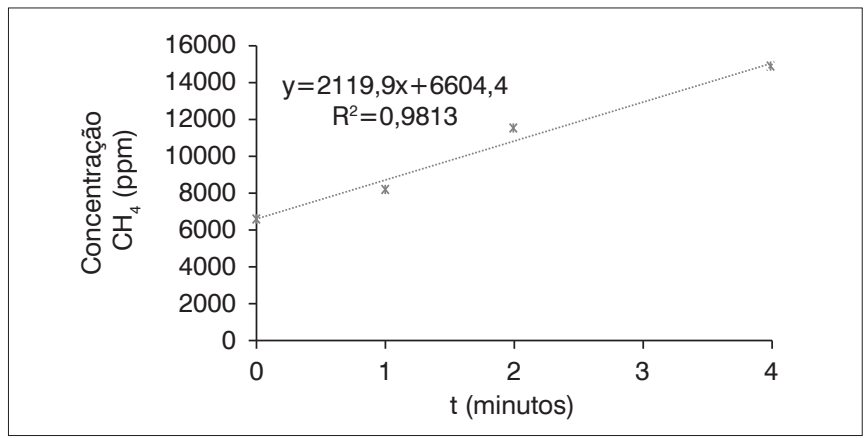

Figura 4 - Ajuste do resultado da análise da concentração de $\mathrm{CH}_{4}$.

Tabela 1 - Resultados das determinações de metano no Aterro Bandeirantes.

\begin{tabular}{|c|c|c|c|c|c|}
\hline \multirow[b]{2}{*}{ Pontos } & \multicolumn{4}{|c|}{ Partes por milhão (ppm) $\mathrm{CH}_{4}$} & \multirow{2}{*}{$\begin{array}{c}\text { Emissão } \\
\mathrm{m}^{3} \cdot \mathrm{CH}_{4} \cdot \mathrm{m}^{-2} \cdot \mathrm{h}^{-1}\end{array}$} \\
\hline & 0 minuto & $\begin{array}{c}1 \\
\text { minuto }\end{array}$ & 2 minutos & 4 minutos & \\
\hline 1 & 48,50 & 49,00 & 44,30 & 48,80 & 0,00000 \\
\hline 2 & 6629,00 & 8237,00 & 11526,00 & 14865,00 & 0,00537 \\
\hline 3 & 178,00 & 293,00 & 508,00 & 686,00 & 0,00033 \\
\hline 4 & 43,50 & 22,10 & 27,00 & 25,90 & 0,00000 \\
\hline 5 & 53,00 & 59,00 & 44,30 & 45,30 & $-0,000007^{*}$ \\
\hline 6 & 262,00 & 468,00 & 514,00 & 948,00 & 0,00042 \\
\hline 7 & 5,44 & 8,84 & 13,40 & 60,70 & 0,00003 \\
\hline 8 & 3,52 & 9,92 & 18,30 & 19,80 & 0,00001 \\
\hline 9 & 34,20 & 178,00 & 195,00 & 10,80 & 0,00020 \\
\hline 10 & 320,00 & 533,00 & 991,00 & 1020,00 & 0,00045 \\
\hline 11 & 16,30 & 11,60 & 13,60 & 12,00 & 0,00000 \\
\hline 12 & 555,00 & 1042,00 & 1149,00 & 2646,00 & 0,00129 \\
\hline 13 & 36,40 & 24,80 & 32,00 & 53,60 & 0,00001 \\
\hline 14 & 4,06 & 2,05 & 6,38 & 6,84 & 0,0000 \\
\hline 15 & 1,89 & 1,92 & 1,93 & 1,58 & 0,00000 \\
\hline Média (1-15), Área 1 & 546,05 & 729,35 & 1005,61 & 1363,35 & 0,00054 \\
\hline 16 & 7,70 & 7,66 & 17,70 & 419,00 & 0,00026 \\
\hline 17 & 166,00 & 161,00 & 244,00 & 239,00 & 0,00005 \\
\hline 18 & 7,80 & 3,78 & 4,00 & 3,51 & $-0,000002$ \\
\hline 19 & 936,00 & 65,00 & 22094,00 & 6923,00 & 0,00561 \\
\hline 20 & 612,00 & 701,00 & 43,10 & 2156,00 & 0,00103 \\
\hline 21 & 406,00 & 1882,00 & 11018,00 & 18363,00 & 0,01212 \\
\hline 22 & 3,14 & 3,13 & 3,36 & 3,02 & 0,00000 \\
\hline 23 & 4,99 & 4,74 & 2,96 & 2,59 & 0,00000 \\
\hline 24 & 215,00 & 29,10 & 65,00 & 361,00 & 0,00029 \\
\hline 25 & 5289,00 & 13350,00 & 12573,00 & 20562,00 & 0,00871 \\
\hline 26 & 13,30 & 14,30 & 16,50 & 24,70 & 0,00000 \\
\hline 27 & 973,00 & 2638,00 & 3720,00 & 3799,00 & 0,00167 \\
\hline 28 & 6,14 & 6,84 & 6,88 & 7,13 & 0,00000 \\
\hline 29 & 4,62 & 6,14 & 4,40 & 4,24 & 0,00000 \\
\hline 30 & 5,40 & 4,64 & 2,59 & 4,03 & 0,00000 \\
\hline Média (16-30), Área 2 & 576,67 & 1258,49 & 3321,03 & 3524,75 & 0,00198 \\
\hline Média geral & 561,36 & 993,92 & 2163,32 & 2444,05 & 0,00126 \\
\hline
\end{tabular}

Valores negativos indicam absorção, estes pontos encontram-se próximos aos drenos verticais e provavelmente podem ser influenciados pelo sistema de captação do biogás no aterro (sucção ativa). Pontos 1 a 15: área 1, resíduo mais recente. Pontos 16 a 30: área 2, resíduo mais antigo. 
na área com resíduo mais recente do que naquela com o mais antigo. As variações encontradas da emissão de metano mostram que diversos aspectos ambientais podem interferir nas emissões dos gases pela camada de cobertura do aterro, que variam desde as características do solo, tais como: tipo, grau de compactação e de saturação, qualidade da espessura da camada de cobertura, pressões dos gases no contato resíduo-solo-atmosfera, condições climáticas e idade dos resíduos, entre outros (MARIANO, 2008; MARIANO \& JUCÁ, 2010; MACIEL \& JUCÁ, 2011).

A Tabela 2 apresenta o número de drenos para captar biogás por área; a vazão média de metano medida nos drenos em cada área, obtida a partir do sistema de captação do biogás no aterro; a vazão total de metano, calculada a partir do número de drenos; a vazão média nos drenos e o total de emissão por área, calculado considerando a área e a emissão média obtida por meio dos ensaios de campo.

Os valores do total de emissão obtidos foram: 65,86 (área 1 resíduo mais recente) e 401,64 $\mathrm{m}^{3} . \mathrm{CH}_{4} \cdot \mathrm{h}^{-1}$ (área 2 - resíduo mais antigo), como observado na Tabela 2.

A Tabela 3 mostra os resultados obtidos considerando os dados gerais do Aterro Bandeirantes, incluindo informações do Documento de Concepção do Projeto - "Project Design Document"
(PDD) - MDL, dados medidos do sistema de captação do biogás no Aterro Bandeirantes e dados calculados.

No Aterro Bandeirantes existem, no total, 276 drenos verticais para captação do biogás. A vazão total de metano nos drenos do aterro é de $2.610,60 \mathrm{~m}^{3}$. $\mathrm{CH}_{4} \cdot \mathrm{h}^{-1}$, sendo este valor obtido a partir das medições reais de metano, oriundo do sistema de captação de biogás no aterro. A área total do aterro é de $400.000 \mathrm{~m}^{2}$. A emissão média total no aterro foi de $0,00126 \mathrm{~m}^{3} \cdot \mathrm{CH}_{4} \cdot \mathrm{m}^{-2} \cdot \mathrm{h}^{-1}$, sendo este conseguido a partir dos ensaios de campo por meio da placa de fluxo (Tabela 1)

O valor total de emissão $\left(504,00 \mathrm{~m}^{3} \cdot \mathrm{CH}_{4} \cdot \mathrm{h}^{-1}\right)$ obtido foi calculado considerando a área e a emissão média total do aterro. O total de captação $\left(3.114,60 \mathrm{~m}^{3} . \mathrm{CH}_{4} \cdot \mathrm{h}^{-1}\right)$ obtido foi calculado a partir do valor da vazão total dos drenos (real) e o total de emissão (Tabela 3).

A eficiência total (84\%) foi obtida a partir do valor total real dos drenos e o total de captação (valor real + emissão). A fuga (16\%) foi calculada considerando a eficiência total mensurada. A eficiência (75\%) do PDD refere-se ao valor teórico utilizado no projeto de MDL do aterro. A vazão total $\left(4.658,50 \mathrm{~m}^{3} \cdot \mathrm{CH}_{4} \cdot \mathrm{h}^{-1}\right)$ foi obtida a partir do valor teórico aplicado no projeto de MDL do aterro. A eficiência (67\%) obtida foi calculada utilizando o total de captação

Tabela 2 - Dados comparativos de produção e emissão no Aterro Bandeirantes.

\begin{tabular}{lcc} 
Item & $\begin{array}{c}\text { Área 1 } \\
\text { (resíduo mais recente) }\end{array}$ & $\begin{array}{c}\text { Área 2 } \\
\text { (resíduo mais antigo) }\end{array}$ \\
\hline Número de drenos para captação do biogás & 64 & 151 \\
\hline Vazão média dos drenos $\left(\mathrm{m}^{3} \cdot \mathrm{CH}_{4} \cdot \mathrm{h}^{-1}\right)^{\star}$ & 7,15 & 11,17 \\
\hline Vazão total dos drenos $\left(\mathrm{m}^{3} \cdot \mathrm{CH}_{4} \cdot \mathrm{h}^{-1}\right)^{\star *}$ & 457,6 & $1.686,32$ \\
\hline Área $\left(\mathrm{m}^{2}\right)$ & 121.522 & 202.341 \\
\hline Emissão média $\left(\mathrm{m}^{3} \cdot \mathrm{CH}_{4} \cdot \mathrm{m}^{-2} \cdot \mathrm{h}^{-1}\right)^{\star \star *}$ & 0,000542 & 0,001985 \\
\hline Total de emissão $\left(\mathrm{m}^{3} \cdot \mathrm{CH}_{4} \cdot \mathrm{m}^{-2} \cdot \mathrm{h}^{-1}\right)^{\star *}$ & 65,86 & 401,64
\end{tabular}

*valor obtido das medições, a partir do sistema de captação do biogás no aterro; **valores calculados; ***valor obtido por meio dos ensaios de campo (placa de fluxo).

Tabela 3 - Dados de produção, modelagem, emissão e eficiência no Aterro Bandeirantes.

\begin{tabular}{|c|c|}
\hline Item & Valores \\
\hline Número total de drenos para captar biogás no aterro & 276 \\
\hline Vazão total real dos drenos $\left(\mathrm{m}^{3} \cdot \mathrm{CH}_{4} \cdot \mathrm{h}^{-1}\right)$ & $2.610,60$ \\
\hline Área total do projeto $\left(\mathrm{m}^{2}\right)$ & 400.000 \\
\hline Emissão média total $\left(\mathrm{m}^{3} \cdot \mathrm{CH}_{4} \cdot \mathrm{m}^{-2} \cdot \mathrm{h}^{-1}\right)^{*}$ & 0,00126 \\
\hline Total de emissão $\left(\mathrm{m}^{3} \cdot \mathrm{CH}_{4} \cdot \mathrm{h}^{-1}\right)^{\star \star}$ & 504,00 \\
\hline Total de captação (valor real + emissão), $\mathrm{m}^{3} \cdot \mathrm{CH}_{4} \cdot \mathrm{h}^{-1 \star *}$ & $3.114,60$ \\
\hline Eficiência total (considerando a vazão e a emissão total) ${ }^{\star *}$ & $84 \%$ \\
\hline Fuga total ${ }^{\star \star}$ & $16 \%$ \\
\hline Eficiência usada na modelagem do projeto (PDD) ${ }^{\star \star \star}$ & $75 \%$ \\
\hline Vazão total usada na modelagem do projeto (PDD), $\mathrm{m}^{3} \cdot \mathrm{CH}_{4} \cdot \mathrm{h}^{-1 * * *}$ & $4.658,50$ \\
\hline Eficiência (total de captação e vazão total do PDD)** & $67 \%$ \\
\hline Eficiência atual** & $56 \%$ \\
\hline
\end{tabular}


(valor real + emissão) e a vazão total na modelagem do projeto (PDD). A eficiência atual (56\%) foi calculada por meio da vazão total real dos drenos e da vazão total usada na modelagem do projeto, PDD (Tabela 3).

A eficiência atual (56\%) é menor do que a anteriormente utilizada na modelagem do projeto, PDD (75\%). Esse resultado pode ocorrer devido à influência da fuga de metano pela superfície do aterro, que foi calculada e representou 16\%, sendo esta mensurada a partir da eficiência total calculada, considerando-se a vazão total real dos drenos e o total de captação (valor real + emissão). Estudos mostram que as emissões fugitivas de metano pela camada de cobertura representam até $22 \%$ do total das emissões de gases nos aterros sanitários (MARIANO \& JUCÁ, 2010; MACIEL \& JUCÁ, 2011).

A produção de biogás ao longo do tempo nos aterros sanitários é estimada por meio de modelos matemáticos. A maioria dos modelos considera, para os cálculos dados, em sua maioria, empíricos, a quantidade de resíduos orgânicos, a condição operacional e de gerenciamento do aterro, a fração de metano do biogás e, principalmente, a eficiência de captação de biogás do projeto. O fato de a maioria das modelagens não considerarem dados reais, como a composição gravimétrica adequada, os aspectos climáticos e o tipo de cobertura final do aterro, por exemplo, tem resultado em grandes distorções entre os valores reais encontrados e os mensurados nos projetos de MDL (ENSINAS, 2003; BOSCOV, 2008; MACHADO et al., 2009; SILVA, 2010; MACIEL \& JUCÁ, 2011).

Estudos em 29 aterros sanitários com projetos de MDL registrados na United Nations Framework Convention on Climate Change (ONU/UNFCCC), incluindo brasileiros e internacionais, mostram reduzidos valores (34\%) de sucesso em relação à produção real de créditos de carbono comparados à modelagem teórica adotada em seus projetos (PDD). Um dos dados de entrada que mais afeta o cálculo final destas modelagens é a eficiência de captação do biogás. O que se usa atualmente é um valor padrão fixo que varia entre 60 a $80 \%$ de eficiência. Para uma correta estimativa deste valor faz-se necessário o estudo contínuo das emissões fugitivas superficiais de metano no aterro sanitário, pois essa questão depende muito das particularidades de concepção dos projetos (SPOKAS et al., 2006; MACHADO et al., 2009; KWON; CHO; KIM, 2009, CANDIANI, 2011).

\section{Aterro Caieiras}

A Tabela 4 demonstra os resultados obtidos nos pontos amostrados pelos ensaios de campo da emissão de metano no Aterro Caieiras. Os cálculos realizados foram os mesmos descritos anteriormente, porém as emissões são apresentadas de acordo com cada fase de operação do aterro. Assim, as emissões médias obtidas foram as seguintes: fase I com $0,00134 \mathrm{~m}^{3} \mathrm{CH}_{4} \cdot \mathrm{m}^{-2} \mathrm{~h}^{-1}$, fase II com $0,01059 \mathrm{~m}^{3} \mathrm{CH}_{4} \cdot \mathrm{m}^{-2} \mathrm{~h}^{-1}$ e Fase III com $0,01836 \mathrm{~m}^{3} \cdot \mathrm{CH}_{4} \cdot \mathrm{m}^{-2} \cdot \mathrm{h}^{-1}$, apresentando média geral de $0,01222 \mathrm{~m}^{3} \cdot \mathrm{CH}_{4} \cdot \mathrm{m}^{-2} \cdot \mathrm{h}^{-1}$.

A Tabela 5 mostra o número de drenos para captação do biogás por fase do aterro, a área total de cada fase, a emissão média de metano e o total de emissão, sendo este calculado a partir da área total de cada fase e a emissão média de metano. Destaca-se o total emitido pela fase III (resíduo mais recente) do aterro $\left(2.019,6 \mathrm{~m}^{3} \cdot \mathrm{CH}_{4} \cdot \mathrm{m}^{-2} \cdot \mathrm{h}^{-1}\right)$, maior valor comparado com as outras. $\mathrm{Na}$ fase I os resíduos foram depositados há seis e oito anos; portanto, é um resíduo mais antigo, comparando-se com a fase II em que os resíduos foram depositados entre três e cinco anos e com a III, na qual eles foram depositados mais recentemente, aproximadamente a dois anos. Analisando esse fato, observa-se que os valores das emissões são maiores nas fases mais recentes do aterro (Tabela 5).

Esse resultado corrobora com a curva teórica da geração de metano em condições anaeróbias nos aterros sanitários, onde nos primeiros anos há um pico de geração (fase metanogênica) e gradativamente existe uma tendência de estabilização e finalmente queda na produção de biogás (FARQUHAR \& ROWERS, 1973; POHLAND, 1975; HOEKS, 1983; TCHOBANOGLOUS THEISEN; VINIL, 1993; OONK, 2010; CANDIANI, 2011). Porém, nos aterros sanitários brasileiros devido à infraestrutura, aos recursos financeiros e às condições operacionais, nas fases iniciais é que se caracterizam as menores taxas de eficiência em relação à captação dos gases, pois muitos aterros sanitários começam as operações sem a implantação adequada do sistema de captação do biogás (SILVA \& CAMPOS, 2008).

De forma geral, as curvas da produção de biogás nos aterros sanitários brasileiros apresentam uma tendência elevada na produção, enquanto o aterro está em operação, ou seja, recebendo os resíduos sólidos urbanos com altas frações orgânicas (50\%). Porém, como os resíduos orgânicos presentes em maior quantidade apresentam taxas de biodegradação rápida, as maiores produções de biogás tendem a ocorrer, principalmente, nos anos iniciais de vida destes aterros. Após o encerramento de suas operações, ou seja, quando não há entrada mais de resíduo, as taxas da produção de biogás se reduzem rapidamente (SILVA \& CAMPOS, 2008; SILVA, 2010; CANDIANI, 2011).

A Tabela 6 apresenta os resultados, considerando os dados gerais do Aterro Caieiras, incluindo informações do PDD - MDL, dados medidos do sistema de captação do biogás no Aterro Caieiras e dados calculados.

O Aterro Caieiras possui um total de 170 drenos verticais para captação do biogás. A vazão total de metano nos drenos do aterro é de 7.250,00 $\mathrm{m}^{3} \cdot \mathrm{CH}_{4} \cdot \mathrm{h}^{-1}$, sendo este valor obtido a partir das medições reais de metano, proveniente do sistema de captação de biogás no aterro. Sua área total é de $330.000 \mathrm{~m}^{2}$. A emissão média total foi de $0,01222 \mathrm{~m}^{3} \cdot \mathrm{CH}_{4} \cdot \mathrm{m}^{-2} \cdot \mathrm{h}^{-1}$, sendo este 
Tabela 4 - Resultados das determinações de metano no Aterro Caieiras.

\begin{tabular}{|c|c|c|c|c|c|c|}
\hline \multirow[b]{2}{*}{ Pontos } & \multirow[b]{2}{*}{ Fases } & \multicolumn{4}{|c|}{ Partes por milhão (ppm) $\mathrm{CH}_{4}$} & \multirow[b]{2}{*}{$\mathrm{m}^{3} \cdot \mathrm{CH}_{4} \cdot \mathrm{m}^{-2} \cdot \mathrm{h}^{-1}$} \\
\hline & & $\begin{array}{c}0 \\
\text { minuto }\end{array}$ & $\begin{array}{c}1 \\
\text { minuto }\end{array}$ & $\stackrel{2}{\text { minutos }}$ & $\begin{array}{c}4 \\
\text { minutos }\end{array}$ & \\
\hline 1 & I & $2.487,00$ & $1.353,00$ & $5.645,00$ & $9.821,00$ & 0,00513 \\
\hline 2 & I & 114,00 & 50,88 & 55,68 & 53,12 & $-0,00002$ \\
\hline 3 & I & 572,40 & 2,09 & $1.025,00$ & $1.028,00$ & 0,00028 \\
\hline 4 & I & 132,50 & 53,76 & 81,28 & 94,72 & $-0,00001$ \\
\hline Média da fase I & - & 826,48 & 364,93 & $1.701,74$ & $2.749,21$ & 0,00134 \\
\hline 5 & ॥ & 890,20 & $1.153,00$ & $1.318,00$ & $1.459,00$ & 0,00033 \\
\hline 6 & II & $7.345,00$ & $10.766,00$ & $13.566,00$ & $18.016,00$ & 0,00654 \\
\hline 7 & II & $1.131,00$ & 193,20 & 139,80 & 173,00 & 0,00000 \\
\hline 15 & II & $370.286,00$ & $177.006,00$ & $219.794,00$ & $407.589,00$ & 0,05439 \\
\hline 16 & II & $62.842,00$ & $2.457,00$ & $2.481,00$ & $2.814,00$ & 0,00031 \\
\hline 17 & ॥ & $6.044,00$ & $12.966,00$ & $73.553,00$ & $69.760,00$ & 0,04409 \\
\hline 18 & II & $1.713,00$ & $1.261,00$ & $1.810,00$ & $1.856,00$ & 0,00019 \\
\hline 19 & II & $1.519,00$ & $2.016,00$ & 3,44 & $3.533,00$ & 0,00125 \\
\hline 20 & II & $4.029,00$ & $4.267,00$ & $4.269,00$ & $7.004,00$ & 0,00187 \\
\hline 21 & II & $9.602,00$ & $10.328,00$ & $6.954,00$ & $21.676,00$ & 0,00738 \\
\hline 25 & ॥ & 863,10 & 850,10 & 931,90 & $1.062,00$ & 0,00013 \\
\hline Média da fase II & - & $42.387,66$ & $20.296,66$ & $29.529,10$ & $48.631,09$ & 0,01059 \\
\hline 8 & III & 241,30 & 355,20 & 487,00 & 758,50 & 0,00032 \\
\hline 9 & III & $4.953,00$ & $9.427,00$ & $19.068,00$ & $39.142,00$ & 0,02192 \\
\hline 10 & III & $1.009,00$ & 767,40 & $1.020,00$ & $1.256,00$ & 0,00021 \\
\hline 11 & III & 865,70 & $1.719,00$ & $2.585,00$ & $3.302,00$ & 0,00149 \\
\hline 12 & III & $45.531,00$ & $117.943,00$ & $169.874,00$ & $258.194,00$ & 0,12948 \\
\hline 13 & III & 626,70 & 420,80 & 702,40 & 483,50 & $-0,00004$ \\
\hline 14 & III & $3.110,00$ & $8.781,00$ & $10.958,00$ & $16.437,00$ & 0,00787 \\
\hline 22 & III & 372,00 & 555,00 & 768,00 & $1.847,00$ & 0,00093 \\
\hline 23 & III & $21.112,00$ & $35.318,00$ & $28.729,00$ & $56.225,00$ & 0,01998 \\
\hline 24 & III & $3.592,00$ & $3.805,00$ & $1.962,00$ & $6.190,00$ & 0,00150 \\
\hline Média da fase III & - & $8.141,27$ & $17.909,14$ & $23.615,34$ & $38.383,50$ & 0,01836 \\
\hline Média geral & - & $22.039,32$ & $16.152,58$ & $22.711,22$ & $37.190,95$ & 0,01222 \\
\hline
\end{tabular}

Valores negativos indicam absorção, estes pontos encontram-se próximos aos drenos verticais e provavelmente podem ser influenciados pelo sistema de captação do biogás no aterro (sucção ativa). Pontos 1 a 4: fase I; 5 a 25: fase II e 8 a 24: fase III.

Tabela 5 - Dados comparativos de produção e emissão no Aterro Caieiras.

\begin{tabular}{lccc} 
Item & Fase I & Fase II & Fase III \\
Número de drenos para captação do biogás & 28 & 85 & 57 \\
\hline Área $\left(\mathrm{m}^{2}\right)$ & 55.000 & 165.000 & 110.000 \\
Emissão média $\left(\mathrm{m}^{3} \cdot \mathrm{CH}_{4} \cdot \mathrm{m}^{-2} \cdot \mathrm{h}^{-1}\right)^{*}$ & 0,00134 & 0,01059 & 0,01836 \\
\hline Total de emissão $\left(\mathrm{m}^{3} \cdot \mathrm{CH}_{4} \cdot \mathrm{m}^{-2} \cdot \mathrm{h}^{-1}\right)^{\star *}$ & 73,7 & $1.747,3$ & $2.019,6$ \\
\hline
\end{tabular}

*valor obtido por meio dos ensaios de campo (placa de fluxo); **valor calculado.

Tabela 6 - Dados de produção, modelagem, emissão e eficiência no Aterro Caieiras.

\begin{tabular}{|c|c|}
\hline Item & Valores \\
\hline Número total de drenos para captação do biogás no aterro & 170 \\
\hline Vazão total real dos drenos $\left(\mathrm{m}^{3} \cdot \mathrm{CH}_{4} \cdot \mathrm{h}^{-1}\right)$ & $7.250,00$ \\
\hline Área total do projeto $\left(\mathrm{m}^{2}\right)$ & 330.000 \\
\hline Emissão média total $\left(\mathrm{m}^{3} \cdot \mathrm{CH}_{4} \cdot \mathrm{m}^{-2} \cdot \mathrm{h}^{-1}\right)^{*}$ & 0,01222 \\
\hline Total de emissão $\left(m^{3} \cdot \mathrm{CH}_{4} \cdot \mathrm{h}^{-1}\right)^{\star \star}$ & $3.840,6$ \\
\hline Total captação (valor real + emissão), $\mathrm{m}^{3} \cdot \mathrm{CH}_{4} \cdot \mathrm{h}^{-1 * *}$ & $11.092,94$ \\
\hline Eficiência total (considerando a vazão e a emissão total) ${ }^{\star \star}$ & $65 \%$ \\
\hline Fuga total ${ }^{\star *}$ & $35 \%$ \\
\hline Eficiência usada na modelagem do projeto (PDD) ${ }^{\star \star \star}$ & $75 \%$ \\
\hline Vazão total usada na modelagem do projeto (PDD), $\mathrm{m}^{3} \cdot \mathrm{CH}_{4} \cdot \mathrm{h}^{-1 * * *}$ & $11.570,00$ \\
\hline Eficiência (total de captação e vazão total do PDD) ${ }^{\star \star}$ & $96 \%$ \\
\hline Eficiência atual** & $63 \%$ \\
\hline
\end{tabular}


valor obtido a partir dos ensaios de campo por meio da placa de fluxo (Tabela 4). O valor total de emissão $\left(3.840,6 \mathrm{~m}^{3} \cdot \mathrm{CH}_{4} \cdot \mathrm{h}^{-1}\right)$ foi calculado considerando a área e a emissão média em cada fase do aterro. O total de captação $\left(11.092,94 \mathrm{~m}^{3} \cdot \mathrm{CH}_{4} \cdot \mathrm{h}^{-1}\right)$ foi calculado a partir do valor da vazão total dos drenos (real) e do total de emissão (Tabela 5).

A eficiência total (65\%) foi determinada a partir do valor total real dos drenos e do total de captação (valor real + emissão). A fuga (35\%) obtida foi calculada considerando-se a eficiência total mensurada. A eficiência (75\%) do PDD refere-se ao número teórico utilizado no projeto de MDL do aterro. A vazão total $\left(11.570,00 \mathrm{~m}^{3} \cdot \mathrm{CH}_{4} \cdot \mathrm{h}^{-1}\right)$ aplicada foi obtida a partir do valor teórico usado no projeto de MDL do aterro. A eficiência (96\%) obtida foi calculada utilizando o total de captação (valor real + emissão) e a vazão total usada na modelagem do projeto (PDD). A eficiência atual (63\%) foi calculada usando a vazão total real dos drenos e a vazão total usada na modelagem do projeto (PDD), como visto na Tabela 3.

A eficiência atual obtida (63\%) é menor do que a anteriormente utilizada na modelagem do projeto, PDD (75\%), resultado que corrobora com as diferenças apontadas entre os valores reais obtidos pelos sistemas de captação de biogás e aqueles dos projetos de MDL, a partir das modelagens matemáticas utilizadas. A fuga total encontrada (35\%) no Aterro Caieiras é significativa e acaba influenciando os resultados de eficiência do sistema de captação de biogás no aterro. A emissão de biogás (fuga), por meio da camada de cobertura no aterro, representa impacto ambiental pela emissão do metano na atmosfera (efeito estufa) e também redução no aproveitamento dos créditos de carbono e energético do mesmo. Esse significativo escape de metano pela superfície do aterro pode ocorrer devido à perda de eficiência da camada de solo de cobertura (redução da qualidade em relação às condições ambientais e climáticas), ao número inadequado de drenos verticais ou necessidade de conectá-los ao sistema de captação de biogás, à presença de trincas e fissuras na camada de cobertura e à necessidade de aumentar pressão de sucção do biogás no aterro (ENSINAS, 2003; SILVA \& CAMPOS, 2008; SCHEUTZ et al., 2009; SILVA, 2010; CANDIANI, 2011).

\section{Conclusões}

O estudo realizou ensaios em campo (placa de fluxo) para determinação das emissões fugitivas de metano pela camada de solo de cobertura de dois aterros sanitários de grande porte, subsidiando análises da eficiência dos sistemas de captação de biogás neles. No Aterro Bandeirantes, os ensaios de campo foram realizados em 30 pontos e no Caieiras, em 25. Em cada ponto amostrado, determinou-se a concentração de metano por meio de uma série temporal de quatro medições, sendo que estes valores foram ajustados estatisticamente, resultando em um de coeficiente angular para cada um dos pontos avaliados. Com estes resultados, determinou-se a emissão de metano para cada um dos pontos. As eficiências obtidas foram calculadas a partir das emissões totais médias de metano dos aterros e também dos dados de vazão de metano real (medidos) dos drenos, obtidos dos sistemas de captação de biogás dos aterros. Com base nos resultados obtidos, pode-se concluir que:

- embora os dois aterros sanitários estudados tenham infraestrutura adequada, nota-se a existência de emissões fugitivas de metano pela camada de cobertura (Aterro Bandeirantes com 0,00126 $\mathrm{m}^{3} \mathrm{CH}_{4} \cdot \mathrm{m}^{-2} \mathrm{~h}^{-1}$ e Caieiras, $\left.0,01222 \mathrm{~m}^{3} \mathrm{CH}_{4} \cdot \mathrm{m}^{-2} \mathrm{~h}^{-1}\right)$;

- o ensaio com a placa de fluxo pode contribuir para o mapeamento da fuga de metano pela superfície dos aterros. No Aterro Bandeirantes, a fuga total de metano representou 16\% e no Caieiras, 35\%;

- as eficiências obtidas dos sistemas de captação de biogás nos aterros foram menores quando comparadas àquelas utilizadas na modelagem dos projetos de MDL (PDD) dos aterros. No Aterro Bandeirantes, a eficiência atual obtida foi de 56\% e no Caieiras, 63\%, valores inferiores se comparados com aquela usada nos PDDs (75\%) dos aterros. A fuga de metano pela superfície é um dos fatores que influencia este resultado;

- o maior controle da fuga de biogás nos aterros é de fundamental importância, principalmente em aterros que apresentam projetos de reaproveitamento do metano para produção de créditos de carbono e/ou energia elétrica;

- estudos de emissão fugitiva de biogás pela superfície do aterro são essenciais para modelagens, planejamento e instalação de projetos futuros e também para o acompanhamento da eficiência de captação dos projetos implantados;

- um maior aprofundamento dos estudos das emissões fugitivas em aterro deve ser feito para melhor avaliar as variações observadas, considerando os comportamentos sazonais ao longo do ano. A qualidade do solo de cobertura, que não foi contemplada no presente estudo, também pode ser uma ferramenta importante para o aperfeiçoamento dos estudos, correlacionando-se as emissões com o tipo de solo. Finalmente, estudos quanto à oxidação biológica de metano realizada por micro-organismos presentes no solo da cobertura dos aterros podem contribuir para reduzir a emissão de metano para a atmosfera.

\section{Agradecimentos}

Os autores agradecem a colaboração da pesquisadora Elizabeth Sikar, física da empresa Construmaq São Carlos-SP. Também ao apoio, para realização deste estudo, das empresas Biogás Energia Ambiental S.A. e ESSENCIS Soluções Ambientais S.A. 


\section{Referências}

BABILOTTE, A.; LAGIER, T.; FIANI, E.; TARAMINI, V. (2010) Fugitive Methane Emissions from Landfills: Field Comparison of Five Methods on a French Landfill. Journal of Environmental Engineering, n. 139, p. 777-784.

BOSCOV, M.E.G. (2008) Geotecnia Ambiental. São Paulo: Oficina de Textos.

CANDIANI, G. (2011) Estudo da geração de metano em uma célula de aterro sanitário. Tese (Doutorado) em Energia. Centro de Engenharia, Modelagem e Ciências Sociais Aplicadas, Universidade Federal do ABC, Santo André, São Paulo, 152 p.

ENSINAS, A.V. (2003) Estudo da geração de biogás no aterro sanitário Delta em Campinas - SP. Dissertação (Mestrado em Engenharia Mecânica), Universidade Estadual de Campinas, Campinas, São Paulo, 129 p.

FARQUHAR, G.J. \& ROWERS, F.A. (1973) Gas production during refuse decomposition. Water, Air and Soil Pollution, v. 12, n. 14, p. 483-495.

HOEKS, J. (1983) Significance of biogas reduction in waste tips. Waste Management \& Research, v. 1, p. 323-325.

IPCC - Intergovernmental Panel on Climate Change. (2006) Guidelines for National Greenhouse Inventories: Reference Manual, v. 3. Disponível em: <http://www.ipcc-nggip.iges.or.jp/public/gl/invs6>. Acesso em: mar. 2011.

IPT - Instituto de Pesquisas Tecnológicas. (2000) Lixo municipal: manual de gerenciamento integrado. São Paulo: IPT/CEMPRE.

KWON, K.R.; CHO, H.S.; KIM, J.Y. (2009) Two Major Issues on Estimation of CER's Potential in CDM Landfill Projects. Proceedings Sardinia 2009, $20^{\text {th }}$ International Waste Management and Landfill Symposium, Sardinia, Italy; 05-09 October.

MACHADO, S.L.; CARVALHO, M.F.; GOURC, J.P.; VILAR, O.M.; NASCIMENTO, J.C.F. (2009) Methane generation in tropical landfills: simplified methods and field results. Waste Management, v. 29, p. 153-161.

MACIEL, F.J. \& JUCÁ, J.F.T. (2011) Evaluation of landfill gas production and emissions in a MSW large-scale Experimental Cell in Brazil. Waste Management, v. 31, p. 966-977.

MARIANO, M.O.H. (2008) Avaliação da retenção de gases em camadas de cobertura de aterros de resíduos sólidos. Tese (Doutorado) em Engenharia Civil, Universidade Federal do Pernambuco, Recife, Pernambuco, $225 \mathrm{p}$

MARIANO, M.O.H. \& JUCÁ, J.F.T. (2010) Ensaios de campo para determinação de emissões de biogás em camadas de cobertura de aterros de resíduos sólidos. Revista Engenharia Sanitária Ambiental, v. 15 , n. 3, p. 223-228
NETO, J.B. (2009) Medidas da emissão de gases em oito aterros de resíduos sólidos urbanos no estado de São Paulo, Brasil. Tese (Doutorado) em Engenharia Ambiental, Escola de Engenharia de São Carlos, Universidade de São Paulo, São Carlos, São Paulo, 530 p.

OONK, H. (2010) Literature review: methane from landfills: methods to quantify generation, oxidation and emission. Innovations in Environmental Technology, The Netherlands, Oonkay.

POHLAND, F.G. (1975) Sanitary landfill stabilization with leachate recycle and residual treatment. EPA-660/2-75-043, US Environmental Protection Agency.

SCHEUTZ, C.; KJELDSEN, P.; BOGNER, J.E.; DE VISSCHER A.; GEBERT, J.; HILGER, H.A.; HUBER-HUMER, M.; SPOKAS, K. (2009) Microbial methane oxidation processes and technologies for mitigation of landfill gas emissions. Waste Management \& Research, v. 27, p. $409-455$

SILVA, E.R. (2010) Modelagem Matemática da Produção e Transporte de Biogás em Aterros Sanitários. Dissertação (Mestrado em Energia), Universidade Federal do ABC, Santo André, São Paulo, 82 p.

SILVA, T.N. \& CAMPOS, L.M.S. (2008) Avaliação da produção e qualidade do gás de aterro para energia no aterro sanitário dos Bandeirantes-SP Revista Engenharia Sanitária Ambiental, v. 13, n. 1, p. 88-96

SPOKAS, K.; BOGNER, J.; CHANTON, J.P.; MORCET, M.; ARAN, C.; GRAFF, C.; MOREAU-LE GOLVAN, Y.; HEBE, I. (2006) Methane mass balance at three landfill sites: What is the efficiency of capture by gas collection systems? Waste Management, v. 26, p. 516-525.

SWANA - The Solid Waste Association of North America. (1998) Comparison of Models for Predicting Landfill Methane Recovery. Publication GR-LG 0075. SWANA: Dallas, TX-USA.

TCHOBANOGLOUS, G.; THEISEN, H.; VINIL, S. (1993) Integrated Solid Waste Management: Engineering principles and management issues. New York, USA: McGraw-Hill Inc., 938 p.

TEIXEIRA, C.E.; TORVES, J.C.; FINOTTI, A.R.; FEDRIZZI, F.; MARINHO, F.A.M. (2009) Estudos sobre a oxidação aeróbia do metano na cobertura de três aterros sanitários no Brasil. Revista Engenharia Sanitária Ambiental, v. 14, n. 1, p. 99-108.

USEPA - United States Environmental Protection Agency. (1998) Landfill gas emissions model, version 3.02 user's guide - LandGEM. Disponível em: $<$ http://mww.epa.gov/ttncatc1/dir1/landgem-v302-guide.pdf > . Acesso em fev. 2010

USEPA - United States Environmental Protection Agency (2005). Firstorder kinetic gas generation model parameters for wet landfills. EPA600/R-05/072, EPA: Washington, DC-USA. 